\title{
PREDATOR STUDIES IN MICHIGAN WATERS
}

\author{
J. Clark Salyer \\ Institute for Fisheries Research, \\ University of Michigan
}

Studies of fish predators, with particular reference to those affecting inland lake and stream habitats, have been in progress by the Institute for Fisheries Research since 1930. The methods of study have included stomach examinations, field work to determine predator abundance in relation to fish abundance, and examination of fish found dead in wild waters. The present report is based only upon studies of dead fish received during 1931 and 1932. Most of the specimens were fish which were picked up dead on head screens of trout-rearing stations, of the Michigan Department of Conservation. The head screens at these stations make effective barriers which catch any dead fish which the stream carries down. Since the screens are frequently cleaned by the caretakers the fish are usually found soon after lodging against the barriers. Directions for preserving and labelling the specimens were distributed to caretakers at the beginning of the 1931 field season and large numbers of dead fish have been saved for study each season. Miscellaneous dead trout specimens picked up on several streams by field investigators of the Institute for Fisheries Research during 1931 and 1932 are included in the material upon which the present report is based.

Most of the fish received were in surprisingly good condition. The color of most was bright, the flesh was firm, and the peritoneum was normally pigmented. In the majority of cases the trout were fat and had full stomachs, showing that they had died rather suddenly. The absence of crayfish marks on all but one or two specimens demonstrates the dispatch with which the fish were carried down to the head screens by the current. Crayfish marks are a sure sign of delay in the floating down of the fish to the head screens. Crayfish remove from the stream in 24 hours most dead fish touching the bottom or checked and lodged in backwaters, even trout up to 14 inches in length. These facts were determined in the course of field work on fish predators during 1931 and 1932. The activity of crayfish in consuming dead trout limits to some degree the number of fish which will be carried down to the head screen. In spite of this fact, an adequate number of specimens for this preliminary study was secured from head screens.

The writer is convinced that the cause of death in the fish thus obtained is a valuable aid in estimating the relative severity of predator pressure on the trout streams in comparison with other forms of destruction. The careful recovery, preservation, and label- 
ling of fish from screens will in the course of several seasons yield valuable data as to the degree of predator activity on natural streanis, information which stomach analysis will not always yield. The date, time of day, and any unusual facts, as a run of hot weather, are valuable data to include. The fish were preserved in a solution of one part formalin to ten parts water.

\section{Means of Identifying Cause of Death}

The predators leave a characteristic mark on the fish whereby they can be identified by the experienced worker. Snakes leave a series of punctures grouped in definite vertical lines at right angles to the long axis of the fish's body. These are made in manouvering the fish so as to swallow it head first. The point of seizure is generally apparent also, from rather deep creases and abrasions in that region. The vertical rows of punctures are overlain by a horizontal series of fine striae left by the teeth of the dentigerous bones when the swallowing process is initiated. It is apparent from some of the specimens that trout frequently escape the water snake in the early stages of the swallowing act, and are then subsequently overcome by the onset of fungus. I have not seen a case of recovery from snake wounds, although recoveries from injuries caused by birds and lampreys are rather frequent.

Turtles, especially the larger ones, make large triangular gashes in the body of the fish. A turtle bite is generally fatal. Several small trout among the specimens reported upon evidently had their caudal fins amputated by these agents. A large lamprey (Ichthyomyzon concolor) received from one station, had the posterior half of its body severed by a clean-cut turtle's bite.

Bird nuarks are the most characteristic of all. It is possible to identify the species of bird concerned. The Great Blue Heron can deliver a death-giving thrust with its pointed, closed bill; or slightly opening the bill, can pick up a fish as with a pair of forceps. The fact that the edges of the rami of the bill are somewhat serrated, makes the last-mentioned act more certain. It is untrue that Herons always spear their fish. Most trout up to 7 inches in length in shallow water are taken by the forcep-like action of the bill, which with its halves somewhat opened is driven by the force of the blow well down into and over the sides of the fish. In deeper water, the fish if from 6 to 15 inches in length is always speared. The Great Blue always strikes at the point of the dorsal fin. Rarely in larger fish, 17 to 19 inches, the thrust is given through the back of the head. If the blow is true, the back of the fish is broken. If the blow is not fully centered the result is equally fatal, the side of the fish being gouged out and often the viscera revealed. Those fish that escape the Heron fall certain prey to fungus from their wounds. A Heron rarely misses a medium or large-sized fish. It 
is the smaller fish which most often exhibit healed marks. The stroke of a Great Blue Heron's bill is delivered with such speed as to be fully comparable with the rapidity of the strike of a poisonous reptile or the tongue movements in certain amphibians. After striking the fish, the sharp edges of the bill leave a clean cut pair of converging marks or lines on each side of the fish's body when it is picked up and further manipulated for swallowing. The size of these marks makes them distinctive from the smaller ones left by the American Bittern or by the Green Heron.

The Bittern, commonly called shikepoke or marsh-pump by hatchery men, more frequently spears its fish, often making several neat, rounded punctures deep into the body. The thrusts are made anywhere in the anterior dorsal region from the head to the dorsal fin. Characteristic beak marks are also made in handling fish preparatory to swallowing.

The Belted Kingfisher rarely, if ever, spears its fish. The prey is captured by a forcep-like action of the moderately serrated bill, the force of the down-plunging bird wedging the fish securely in the slightly opened mandibles. The fish is almost invariably seized in the nape region. Due to the Kingfisher's habit of moving the fish backward or forward in the mandibles to balance it while flying or in its efforts to swallow a fish much larger than is possible, the region of the fish between the head and dorsal fin is severely champed and marked with an intricate pattern of fine lines left by the sharp edges of the mandibles. This pattern is a positive clue to the Kingfisher when trout 6 to 8 inches are picked up in the field thus marked, for this bird frequently catches larger fish than it is able to swallow. It is rare for a Kingfisher to swallow a fish longer than 4 inches, although some 5 inches long are managed. The larger fish, although frequently caught, are either dropped by the bird while flying or through its inability to swallow a fish of such size. It is not uncommon to see Kingfishers fly about a stretch of stream for several minutes with a 5 to 8 inch fish only to lose it finally. A Kingfisher suddenly startled will usually drop a fish too large to be immediately swallowed. The same is true when the bird is fired on with a shot-gun, even if the bird is missed.

The peculiarities and marks of fish-eating birds described above have been adequately checked by field observations and the examinations of hundreds of fish from the stomachs of such birds in the course of the writer's study on fish predators.

Mink leave the mark of their characteristic dentition on the side of the fish caught. This is a horseshoe-shaped pattern of punctures.

Lamprey marks appear as round or oval spaces of bare skin on the trout which, if examined closely, show a slightly pitted surface. This applies to healed wounds. The raw or fresh lamprey mark 
is unmistakable. When healed it is interesting to note that the scar is devoid of scales and has lost its ability to secrete the protective mucus. This last statement is true also of healed birds marks which appear as long sears or welts on the side of the fish. How much the loss of the secretory function of these areas is a factor in the ultimate survival of the fish is conjectural, although some mucus invades the denuded area from contiguous, healthy areas. It is significant that many of the fungused trout in this material had bird and lamprey marks in various stages of recovery.

It will be seen that predators are responsible for a large proportion of the fish found dead in streams, after we exclude the heavy mortality due to streams drying up or becoming overly warm, in such years as 1930 and 1931. The number of fish definitely killed by fish-eating birds exceeds all other predator destruction and may be significant (see summary table).

It is regrettable that more cannot be learned of the part disease, aside from predators, plays in the death of head screen fish. In the case of a bacterial disease, the manner of preservation and the time which must elapse between death and finding of the fish, militates against determining the specific organism at work. Still lesions and suppurating surfaces are apparent, as are fungus and ectoparasites, when examined with the aid of a microscope. On the evidence supplied by this report it will be seen that diseases usually play a minor part in causing the death of the fishes which were studied.

Traumatic injuries are evident in a handful of specimens; at the manner of their happening we can only guess. An astonishing number of trout were badly hooked and seemingly died from their injuries. Despite previously described injuries many of the fish died from causes not detectable. They were in good color, fat, with full stomachs, and had no evident injuries.

A total of 153 fish were received by the Institute, of which 119 were trout and 34 were non-game fish.

Each specimen was measured, examined carefully inside and outside for injuries or disease, and examined with a microscope for ectoparasites. The causes of death in these fish are discussed under the following heads.

\section{Deaths Due to Each Agency \\ 1. Fish-eating birds}

This group of predators accounted for 32 trout ranging in size from $2 \frac{1}{2}$ to 19 inches. Six other fish were also killed by them. Listed as to species the kill is as follows:

Kingfisher: 17 trout, 1 brook lamprey, 1 common sucker, 1 mud minnow.

Great Blue Heron: 11 trout, 2 muddlers (1 Cottus cognatus, 1 Cottus bairdii). 
Bittern: 4 trout, 1 common sucker.

Green Heron: No trout, 1 yellow perch.

All of these fish had wounds severe enough to have caused the death of each. A few bore bird marks from which they had recovered. Further, it should be remembered that all of these birds disdain dead fish. I have been unable to find the slightest trace of their utilization of fish offal in any instance.

\section{Mink}

One of the fish found dead had clearly been killed by a mink.

\section{Lampreys}

Lampreys were the initial cause of death of 2 trout and of 2 ling or burbots, the abrasions made by these parasites becoming secondarily fungused. A number of the fish concerned in this report show old lamprey scars from which the fish recovered only to subsequently fall a victim to another predator or disease. At the Sturgeon River station an eleven inch rainbow caught by a fisherman in the main stream was turned over to the station man. This fish had had the whole top of the head eroded by lampreys but was healed at the time of capture, was fat and in perfect condition. There was no reason why it should not have been used for food. It might be well to state to the fishing public that fishes bearing healed lamprey or bird scars are perfectly palatable if nothing else appears to be wrong with them.

\section{Diseases}

The role played by disease in the death of these fish can best be understood by reading the cases of the individual fish listed at the end of this report. Twenty trout, 17 long-nose dace, and 1 black-nose dace belong to this group. Some 4 or 5 cases listed in this group doubtless originated from slight abrasions becoming subsequently heavily fungused and spreading over the whole fish.

A heavy infestation of gill lice (Salmonicola edwardsii) was found in six instances in the trout of this group. In four instances out of six, the hatchery attendant mentions a high water temperature for the day on which they were picked up. It is probable that numbers of gill lice interfere with the mechanics of respiration to such an extent that on an abnormally hot day, the fish so infested succumb because of the added physiological strain. At least we have here a good correlation with the two facts. The case of a 10 inch wild brook trout sent in from the Sturgeon River station is full of interest in this connection. This fish got into one of the rearing ponds where it lived for several days, finally dying on a day when the water temperature reached 81 degrees $F$. There were 43 adult gill lice on the gills of this trout. Its nose was some- 
what abraded and there was a recovery-mark of an old lamprey laceration on the caudal peduncle.

A number of the dead trout found in the streams had presumably been killed by the dread disease known as Furunculosis. This hatchery-spread disease is likely to become increasingly serious, in the opinion of the Institute.

The significant loss of trout in streams due to disease confirms the current policy of the Michigan Fish Division in not dumping badly diseased trout into the stream, just to save them. This loss due to disease also stresses the importance of further investigation of trout diseases, in hatcheries as well as in nature.

\section{Snakes}

Snake marks were definitely observable on 3 trout and on 4 muddlers ( 3 Cottus cognatus and $1 C$. bairdii). The onset of fungus completed the work of destruction.

\section{Turtles}

Turtles snapped the caudal fins from 2 trout sent in, and may be responsible for the peculiar injuries listed under the heading of traumatic injuries. A large silver lamprey (Ichthyomyzon concolor) sent in from the Bear Creek station had the posterior half of its body severed by a turtle bite. While examining the Pere Marquette River on July 14, 1931, Dr. Greeley of the Institute for Fisheries Research captured a $21 \mathrm{1} / 2$ pound snapping turtle which had just caught a 17 inch (estimated) brown trout. The trout was fresh and firm and the probability of its being caught by the turtle was strengthened by finding the bones and flesh of a 9 inch brown in this turtle's intestine when the stomach and intestines were analyzed. Dr. Greeley states that the habit of the brown trout in taking refuge under stones and in crevices when disturbed would seem to make it a ready prey for the snapper which regularly investigates such places. Once seized by the snapper's powerful jaws, a trout has little chance to escape alive, even if it should struggle free from the grasp of the snapper.

\section{Nutrition}

Two of the trout were of the type known as "racers" by hatchery men. They were slender, had a compressed head large in proportion to body size, and had empty stomachs with no store of fat.

\section{Hooked fish}

The 19 trout in this group had either the mouth parts or opercular apparatus badly torn, showing plainly the effects of having been hooked. No natural predator would leave similar lacerations. Many were hooked exterior to the mouth parts in the opercular region. One muddler ( $C$. bairdii) had the lower part of mouth and jaw torn out, 
probably by a baited hook. It is significant that many of the hooktorn trout are just under legal size. From the mutilation of some, it is apparent that they were flipped off the hook by lazy fishermen without resorting to the use of the hands, or that the hook was otherwise forcibly jerked out.

\section{Dynamite}

One trout was almost certainly and four others were probably killed by dynamite.

\section{Traumatic injuries}

The name is applied to one type of injury for want of a better term. The three trout included here had the snout portion of the head cut off smoothly and vertically as if it had been done with a knife. Turtles might be responsible, but it is doubtful if they would leave such a clean-cut wound.

\section{Unknown causes}

Twenty trout fall in this group. Examination failed to give any clue to their death. For the most part, they had good color, were unmarked and had food in their stomachs. The high water temperatures recorded at some of the stations may have been a causative factor.

It is well known that many thousands of trout were killed in Michigan during the dry years of 1930 and 1931, especially in the Upper Peninsula. The thousands of small fingerling rainbow trout which were washed against the head screen of the Sturgeon River Rearing Station in Cheboygen County were presumably killed by high temperature.

No doubt many trout are killed in nature by unfavorable environmental conditions. Thus the death of trout and other fishes in the headwaters and the new Hardy Dam, on the Muskegon River in Mecosta county, was probably rightly attributed to the fouling of the water by decomposing vegetable matter. Probably some of the 20 trout of our sample which died of unknown cause, were killed by some bad chemical condition.

It must be emphasized that the figures just given, and summarized in the table do not represent the destruction ratios between the various agents which kill fish in our streams. They refer only to the cause of death of fishes found dead in streams. The actual ratio among predators can only be found by exhaustive stomach analysis. The material for such examinations are being collected from a wide range of stream localities over the state. This latter phase of predator investigation has been intensively followed by the writer in 1931-1932. The present report is merely a corollary of the main line of research. 
Cause of Trout Deaths, Expressed as Per Cent of Sample Killed by Each Lethal Agent

Figures refer only to fish found dead in streams

All predators combined, 33 per cent.

Bird predators, 27 per cent (Kingfisher, 14 per cent; Great Blue Heron, 9 per cent; Bittern, 3 per cent).

Snake predators, 3 per cent (water snake presumably; bites followed by fungus).

Turtle predators, 2 per cent (snapping turtle in part at least).

Lamprey predators, 1 per cent (silvery lamprey only).

Mammal predators, 1 per cent (mink).

Cause unknown (probably high temperatures in large part), 25 per cent. See also note in subtitle to table.

Human agencies, 21 per cent (hooking, 17 per cent; dynamiting, 4 per cent). Note: dynamite proportion doubtless too high, owing to fact that Conservation Officers sent in samples from streams where dynamiting was suspected.

Diseases, 17 per cent. Including bacterial diseases (Furunculosis, etc.), fungus diseases and parasite diseases (gill louse, etc.). Malnutrition, 2 per cent.

Traumatic injuries, 3 per cent (head sheared off clean).

\section{SUMMARY TABLE OP PROBABLE CAUSES OF DEATH OF FISH IN MICHIOAN TROUT STREAMS}

Based on dead fish caught on head screens of rearing statlons and dead trout picked up in streams. Not including several thousend small roinbow trout fingerlings found dead on the head screen of the Sturgeon River station 1931, during a very hot period.

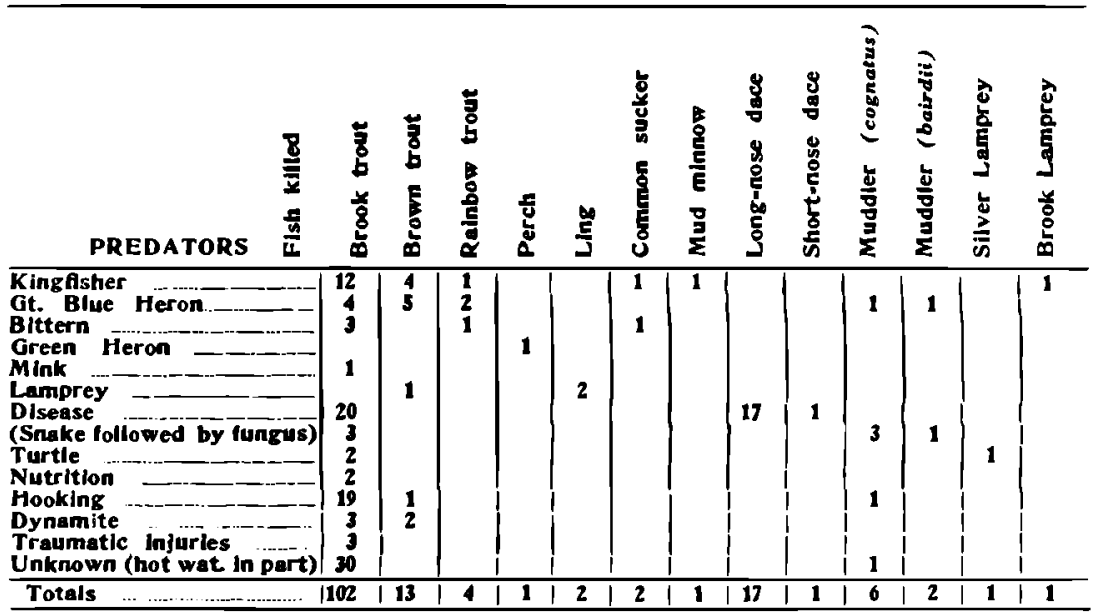

Grand Totel-119 trout plus 34 other fish equals 153 fish. 


\section{Discussion}

Dr. HubBs: I might mention that this paper is presented here merely as a suggested report; the amount of data included in it is entirely insufficient for final analysis of this problem. It is rather a new line of attack on the problem of what kills the fish in the streams, and it is something which should be followed further. We have presented it primarily for the purpose of suggesting this method in case others may wish to follow it through also. The report was written before Mr. Salyer left our work in Michigan about two years ago, and since that time we have acquired a considerable amount of new material along this line, and a much larger amount will be gathered in the future so that the work can be carried further. Mr. Salyer, I might say for the information of those present, has now returned to Michigan and is investigating the problem of the relation of beaver to trout for the Department of Conservation-one of our most extensively argued questions.

Mr. Hogan: We shot a crane on one of our rearing ponds two years ago, and we removed from the stomach of the crane about 125 small bass which were about three-quarters of an inch long, two golden shiners about three inches long, and one crawfish. Besides that, he is protected.

Mr. Grim (Pennsylvania): Does anyone know whether the turtle will catch a large fish?

Dr. Hubrs: There is no question about it; I have seen them do it, and I know it does occur. Just what percentage of the food of the turtle is made up of fish is another problem. Mr. Salyer is including these animals in his further studies of predators. Turtles certainly are capable of catching fish, and most species of turtle do eat fish; as to the percentage that will have to be determined by a continuation of the studies.

Mr. Grim: I caught two snappers this summer; one of them weighed thirtyeight pounds, and I am going to weigh the other one, because my scales would only take forty pounds-it was between forty and fifty pounds. I kept these turtles in a pond with two trout for three weeks; I saw the trout fanning these turtles' noses with their tails, and the trout stayed there for three weeks unharmed. It is just a question whether the turtle will catch the large fish.

DR. HubBS: We ran the same sort of experiment with a considerable number of species of turtles, and every species we tried was found to clean out the fish in short order-all except one snapping turtle; the snapping turtle refused to touch the fish. The snapping turtle is adept at catching prey; our boys in the lakes have seen them catch ducks. The nature of the food in their stomachs indicates conclusively they will catch fish in some degree.

$M_{R}$. CoBb (Connecticut) : Reference has been made to fish having been killed after being hooked. Under normal conditions such as exist around parts of June and July, after a fish has been hooked and played and then released as carefully as the average man would release him, what would be the average chance of that fish-I am referring to trout-coming through without injury? 
Dr. Harkness: Mr. White, working for the Biological Board in New Brumswick, carried out a series of experiments on that problem. After cutting the gill arches of the trout just as they might be torn by a hook, he got a relatively high percentage of recoveries-I think it was 80 per cent. That is published somewhere in the Transactions of the Biological Board of Canada -I am not certain whether in a progress report or in the regular Transactions, but it could be obtained by writing to Dr. H. E. Huntsman at the University of Toronto, or at St. Andrews, New Brunswick.

Mr. COBs: May I ask whether the temperatures were taken in each case?

Dr. Harkness: Of course the temperatures of the waters in which the experiments were carried out would be recorded, but I do not know the details of the experiments. I only know the experiments were conducted, and that was the result. You would have to get the details from the published report.

Mr. Cook (Michigan): At one of the hatcheries in Michigan we have conducted some investigations along that line. For control we used a seine and took fish just under the legal size in one of several ponds, releasing them with as much care as possible, figuring that that would be a fair control over the others. Then we caught one hundred fish by one means or another, using barbed and barbless hooks and flies-dry fly, wet fly and bait, in fact all the different methods that were employed in Michigan-and placed these fish in the various ponds. The following table indicates the result for 1930 and 1932:

\begin{tabular}{|c|c|c|c|}
\hline 1930 & No. of fish used & Loss & $\%$ of loss \\
\hline $\begin{array}{l}\text { Pond No. 1-Caught with artificlal ny, No. } 12 \text { barbed } \\
\text { nook, September 17th } \\
\text { Pond No. 2-Caught with No. } 5 \text { Sproat barbed hook. } \\
\text { natural bait, September } 19=20 \\
\text { Pond No. 3-Caught with No. } 6 \text { Sproat barbless natural } \\
\text { bait, September } 19=20 \\
\text { Pond No. 4-Caught with selne. September } 20\end{array}$ & $\begin{array}{l}200 \\
200\end{array}$ & $\mathbf{5}$ & $\begin{array}{c}21 / 2 \\
101 / 2 \\
91 / 2\end{array}$ \\
\hline $\begin{array}{l}\text { Total loss and percentage based on } 600 \text { fish caught with } \\
\text { hook and line }\end{array}$ & & 45 & $71 / 2$ \\
\hline 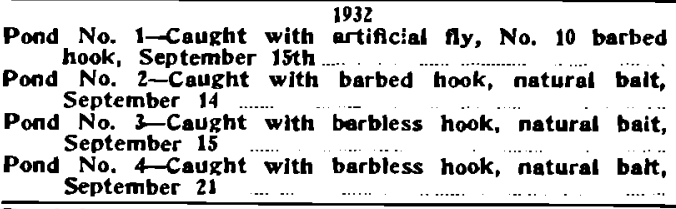 & $\begin{array}{l}200 \\
200 \\
200 \\
100\end{array}$ & $\begin{array}{r}14 \\
7\end{array}$ & $\begin{array}{l}3 \\
7 \\
31 / 2\end{array}$ \\
\hline $\begin{array}{l}\text { Total loss and percentage } \\
\end{array}$ & & 29 & $\overline{41-7}$ \\
\hline
\end{tabular}

NOTE: Fish used in 1930 averaged from five to seven inches in length. Practically all losses occurred within twenty-four hours. Experiment was terminated on October 31 st, 1930 . Fish caught with seine used as a control.

NOTE: Fish used in 1932 ran from three and one-half to seven inches in length, experiment continued thirty days. As in the preceding experiment, the major part of the losses occurred during the first twenty-four hours after hooking.

It is surprising to note that the dry and wet fly made much the best showing, the greater loss, as may be seen from the figures, being among the fish caught with bait. These fish were not caught a second time; in fact they were not subjected to what we would call ordinary stream con- 
ditions. So this year the man working on that has changed his system somewhat; we are catching these fish over again at intervals of about a week, or as soon after they were taken the first time as they would take the fly the second time-sometimes subjecting the ponds to fishing almost continuously-to get some correlation, if possible, with what would be actual stream conditions where the fish are subjected to continuous pounding, you might say, day after day. We hope to be able to present something in this connection to the Society next year, bearing upon the results of the two years' investigation; we felt that the findings were too much of a preliminary character to warrant their presentation this year. 